Small acts, kind words and "not too much fuss": implicit activisms

John Horton \& Peter Kraftl; forthcoming in special issue of Emotion, Space and Society, 2009. 


\title{
Small acts, kind words and "not too much fuss": implicit activisms
}

\begin{abstract}
In this paper, we suggest that social scientists' accounts of 'activism' have too-often tended to foreground and romanticise the grandiose, the iconic, and the unquestionably meaning-ful, to the exclusion of different kinds of 'activism'. Thus, while there is a rich social-scientific literature chronicling a social history of insurrectionary protests and key figures/thinkers, we suggest that there is more to 'activism' (and there are more kinds of 'activism') than this. In short, we argue that much can be learnt from what we term implicit activisms which - being small-scale, personal, quotidian and proceeding with little fanfare - have typically gone uncharted in social-scientific understanding of 'activism'. This paper will reflect upon one example of this kind of 'implicit' activism, by representing findings from interviews undertaken with 150 parents/carers, during an evaluation of a 'Sure Start' Centre in the East Midlands, UK. From these interviews emerged a sense of how the Centre (and the parents/carers, staff and material facilities therein) had come to matter profoundly to these parents/carers. We suggest that these interviews extend and unsettle many social-scientific accounts of 'activism' in three key senses. First: in evoking the specific kinds of everyday, personal, affective bonds which lead people to care. Second: in evoking the kinds of small acts, words and gestures which can instigate and reciprocate/reproduce such care. And third: in suggesting how such everyday, affective bonds and acts can ultimately constitute political activism and commitment, albeit of a kind which seeks to proceed with 'not too much fuss'.
\end{abstract}

Key words: Sure Start, emotion, activism, affect, everyday, family, care 


\section{Small acts, kind words and "not too much fuss": implicit activisms}

\section{Summer, 2005: Part I}

A memo

"[The Sure Start Centre] is currently undergoing a period of uncertainty... and huge upheaval in funding arrangements..." (Sure Start Centre ${ }^{1} 2005$ a unpaginated)

A focus group with staff at the Sure Start Centre

"One thing that... is very worrying for everybody is the fear of funding running out. There is real anxiety about the future, because we all recognise that what we are doing is not a quick fix answer but a long term investment. But what if we are not allowed to do that long-term work? Where will we be then?... There is a lot of fear at the moment. Not just among staff, but among the users too..."

A focus group with users of the Sure Start Centre

"We look out for each other. We try to sort things [out], but with... not too much fuss..."

"But it's a frightening time, with all the cuts. And I dread to think what will happen if we get a Conservative... Council. What will we do if they try to close us down?"

\section{Introduction}

This paper is about a particular place and time: a Sure Start Centre in the East Midlands, UK, in Summer 2005. There and then, as may be evident from our prologue, a particular set of issues and anxieties were becoming palpable (in memos about 'uncertainty' and 'upheaval', for example). For staff and users at the Centre, a sense of foreboding was becoming articulable ('what if we are not allowed to do that long-term work?' 'I dread to think what will happen'). In particular, this paper foregrounds the responses of users of this Sure Start Centre in this context, and reflects upon their nascent demand: "what will we do if they try to close us down?". For we propound these responses this we - as exemplary of a kind of practice which (being politicised, affirmative and potentially transformative) could be construed as activism, but which (being modest, quotidian and proceeding with little fanfare) differs quite markedly from the kinds of activism which have most often captured the imaginations of social scientists.

The paper explores three premises, each of which sits uncomfortably - to some extent - with predominant social-scientific accounts of activism and/or emotion. First, we posit a more complex, ambiguous relationship between emotion and activism. Rather than view particular emotions (such as anger) as a 'resource' for activism, or an outcome of particular activist practices, we demonstrate how constellations of feeling may, sometimes, spill over into activist tendencies that are quite unanticipated and un-planned (as noted by Martin et al., 2007). Hence, second, we seek to question the 'boundaries' of activism - not only between activism and academia (Maxey, 1999) but between 'activism' and 'everyday lives' (Chatterton, 2006). We mobilise a diverse array of feelings and practices, represented in interview quotations from users of the Sure Start Centre. In many cases, we were and are not sure whether those feelings and practices could be termed 'activism', and hope that our account provokes further debate as a result. However, we suggest that at least some of the happenings and dispositions witnessed herein should be conceived as activism: albeit of a sort

\footnotetext{
${ }^{1}$ We anonymise the centre as 'the Sure Start Centre' throughout this paper.
} 
expressed in non-traditional, multiple styles that are quite different from the ostensibly more spectacular practices commonly associated with 'activism'. Third, we suggest that more attention might be accorded to faltering kinds of activism, that proceed with 'not too much fuss'. We open out the progression from everyday lives (at Sure Start) through inflammatory issues, through discernible activisms themselves. We argue that there is no sense of a linear, intentional, inevitable progression from everyday lives and emotions to activism. Rather, we demonstrate how false starts, modest aspirations, changing attitudes and implicit, activist dispositions are inextricably entwined with one another. We prefer, then, a non-linear account of the taking-place of activism that opens out what Jane Jacobs (Jacobs et al., 2007, also Latour, 1988) terms the 'black box' of seemingly assured achievements - in this case, like 'activism'.

In the following section we provide three introductory contexts for these propositions. First, we introduce Sure Start, locating this UK Government policy initiative in relation to some prevailing national and local political discourses. Second, we introduce our own research in this context, at one particular Sure Start Centre in the East Midlands, UK. Third, we develop an introductory critique of the nature of 'activism' as inscribed in the extant work of many social scientists, identifying a series of recurrent habits - and perhaps a series of lacunae - in the ways in which emotion, activism and everyday lives are considered. Our paper then turns to some characteristics of the activism encountered at the Sure Start Centre, all of which were rendered more visible during the aforementioned 'period of uncertainty' at the Centre. Specifically, we consider: the everyday, personal, affective bonds which had led users to care deeply about 'their' Centre and its users; the kinds of small acts, words and deeds which instigated and sustained such care; and, most significantly in the context of this special issue, the ways in which such everyday, affective bonds and acts ultimately constituted politicised activism and commitments, albeit of a kind which sought to proceed conditionally, temporarily, and with 'not too much fuss'. In conclusion, we identify a number of ways in which this latter kind of activism has too-often gone uncharted in, and challenges the tenor of, many social-scientific renderings of activism. Finally, a postscript sketches several 'outcomes' of the place and time evoked in this paper: in effect, we invite readers to consider whether this should count as 'activism'.

\section{Contexts}

\section{Sure Start}

The 'Sure Start' strategy was conceived by the UK Government in 1997-99 as a 'flagship' project to improve the health, well-being, education and future life chances of children in those communities which the UK Government defines as 'deprived' (Sure Start 2000) ${ }^{2}$. In practice, the strategy entailed the constitution of 'Sure Start Centres', providing venues for locally-managed, multi-agency programmes of childcare, education and healthcare provision for the benefit of local 0-4-year-olds and their parents/carers. Sixty such Centres were opened in 1999 and - although there have been numerous subsequent sub-strategies and changes of nomenclature - there are currently around 1250 Centres, each serving a discrete geographical catchment (Sure Start, 2007).

\footnotetext{
${ }^{2}$ For the specific objectives of the Sure Start strategy, see Sure Start (2002). To trace the inception of Sure Start through UK Government policy documents, see Glass (1999), HM Treasury (2000 Section 24.2). For broader contextual/conceptual information about Sure Start, especially the ways in which the strategy refracts changing relationships between childhood, parenthood and the State, as also manifest in antecedents such as 'Head Start' in the USA, see Cohen et al. (2004), Gustafsson and Driver (2005).
} 
By Summer 2005, however, Sure Start had become the focus for considerable national political and media controversy and critique. National newspapers of diverse political leanings bore front page headlines expressing "[d]oubts over value of $£ 3$ bn Sure Start" (The Guardian 13/9/05) or proclaiming - an oft-used pun, this - "[a] less than Sure Start" (Daily Mail 14/9/05). Indeed, similar headlines proliferated over the next eighteen months: thus Sure Start was branded as "failing" (The Times 18/9/05, Daily Mail 23/2/07, The Guardian 10/7/07), as a "total waste of money" and " $£ 1$ bn pound disaster" (Daily Mail 23/2/07), and so forth.

These headlines principally emerged via reportage of preliminary findings of the National Evaluation of Sure Start (NESS): a six year long evaluation of the impact, implementation and cost-effectiveness of all Sure Start Programmes in England (see Belsky et al. 2007). The raft of NESS findings published in 2005/06 (NESS 2005a, 2005b, Belsky et al. 2006) evaluated Sure Start very positively in many senses ${ }^{3}$; however, the data were only inconclusive in evidencing impacts of Sure Start on children's well-being. This inconclusiveness (read as a lack of positive evidence ${ }^{4}$ ), then, fuelled a sense of Sure Start as a 'failing' 'waste of money' in mass media representations and in national political discourse. Thus, to give one example (from a speech by the UK Leader of the Opposition):

[1]ast Friday, I was in... one of the most deprived wards in the country. I was listening to parents and residents as part of the research I've been doing into how we can give more support to families. I was given a litany of state failure: gangs with guns but police too thinly spread to make much difference. Youth clubs closed and nothing for young people to do. And the usual complaints about the complexity of the tax credits system. But it was when the conversation turned to the local Sure Start project that the air really turned blue. One parent told me bluntly that 'it's a complete and utter waste of three million quid'... I'm a big fan of the thinking behind Sure Start [but], money has been thrown at the problem and is now drying up" (Cameron 2006 unpaginated).

This broad pattern of substantial media and political critique, and this sense that funding for Sure Start could - for critics, should - be about to 'dry up' was refracted in local contexts, in relation to local Sure Start Centres. For example, in Summer 2005, the Sure Start Centre at the heart of this paper faced protracted opposition from Borough and County Councillors (Sure Start Centre 2004 7), critical local media coverage about poor usage of the Centre (Sure Start Centre 2006 16) and "inextricable concerns... about the sustainability of our services" (Sure Start Centre 2005b 2).

\footnotetext{
${ }^{3}$ For instance, amongst other positive indicators, Sure Start was evaluated very positively in terms of its implementation, management, and buildings, and was adjudged as significant and effective in affording play and educational opportunities and empowerment and employability for parents/carers (NESS 2005a).

${ }^{4}$ In a critical caveat to their full report, the NESS team went out of their way to emphasise that their inconclusive data did not prove that Sure Start had had no impact, for "it is clear that the ultimate effectiveness of [Sure Start] cannot be determined for quite some time" (NESS 2005b 1-2); however, this nuance has seldom been acknowledged in mass media and political discourse.
} 


\section{A local evaluation}

Within the above context, the authors were part of a team commissioned in Summer 2005 to conduct a 'local evaluation' of a Sure Start Centre in the East Midlands, UK. At this time, it was a statutory requirement for Sure Start Centres to commission an independent 'local evaluation' every 18-24 months. Central to the evaluation was a programme of semi-structured interviews with parents/carers who used a sample of spaces/services provided by the Sure Start Centre ${ }^{5}$. Members of the evaluation team visited and participated in these spaces/services over a three month period and invited all parents/carers encountered during this time to participate in interviews. In all, 150 parents/carers were consulted in this way, with interviews lasting 30 minutes to one hour. The following pages present a small sample of extracts from these interviews, which were often ad hoc (taking place amidst the hurly burly of a play group session at the Centre, for example) and frequently deeply emotional in content and tenor. We choose not to comment specifically, here, on the added emotive layer provided by the fact that the Centre's activities involved young children, for two reasons. First, because significant previous work has focussed upon the particular, emotive effects and affects provoked by children as idea and ideal (Valentine, 1996; Jenks, 2005; Kraftl, 2006, 2008). Second, because the key relationship between emotion, everyday lives and activism was not necessarily, or specifically, held together by children, but by the kinds of caring relationships (between mothers and children, between Centre users, and between Centre workers and users) promulgated by the Centre. Indeed, it was frequently these relationships - rather than the outcomes for individual children - that were foregrounded in the interviews were at the forefront of Sure Start users' concerns.

\section{Encounters with 'activism'}

It is our contention that the actions of Sure Start users should be conceived as 'activism', but of a kind which seems absent from the rich and burgeoning social-scientific literatures already devoted to this concept. For - drawing, now, on extant critic(isms)s of these literatures - we suggest that social scientists' accounts have overwhelmingly tended to prioritise particular kinds of activist behaviour, and thus typically (re)produce a particular version of activism per se. This prioritisation has been important in elaborating a sense and language for acknowledging the importance of activism within the social-scientific canon. However, we would suggest that that such social-scientific understandings of activism have often (and we emphasise, understandably) had the following related characteristics. We follow our brief review with three critical points that signal not so much the shortcomings of previous work on activism, but rather that highlight the need for a slightly different conception of the emergence of activism with/in everyday lives and emotions - in short, a need to consider 'implicit activisms' (see also Martin et al., 2007).

i). A tendency to prioritise actions which are dramatic, iconic, totemic, "glamorous and heroic" (Pile and Keith 1997 xi), even "salvational" (Lyman 1995 397). For example, Chatterton (2006 270) notes a tendency for many accounts of environmental and/or anti-globalisation activism to highlight spectacular, staged 'actions', whilst problematically deferring attention to more banal, day-to-day practices "of collectively challenging social relations in our everyday lives which we all continually help to reproduce". Elsewhere, likewise, Griffin (2008 94, also 2005) notes a tendency for chief

\footnotetext{
${ }^{5}$ In total, the evaluation project entailed four major lines of research: (i) in-depth interviews with 150 users of the Sure Start Centre; (ii) shorter interviews with 50 parents/carers who were entitled to use the Centre, but did not; (iii) interviews with staff and stakeholders at the Centre; (iv) qualitative projects with young children using the Centre. Being statutorily required at the time, the project was comissioned from the Sure Start Centre's core funding. As such, the research reported here was effectively infrastructural to this Centre, and thus this national policy intervention. We reflect upon some aspects of this situation - social-scientific research in the context of a state-sponsored policy intervention - in a forthcoming paper (Horton and Kraftl, forthcoming). More straightforward summaries of 'policy-relevant' findings/recommendations from the project are available from the authors on request.
} 
historical accounts of protest to focus upon riotous and incendiary practices, neglecting both the everyday contexts and relations of/for such action, and the substantial contemporary import of more covert, less vivid forms of activism.

ii) A tendency to prioritise actions which leave a readily-representable legacy. Of course, often this tendency represents methodological pragmatism (Griffin 2006) or a concerted effort to unpack the affecting visual or textual cultures of past and present activism (for example Pickerill and Webster 2006, Wettergren 2005, Kurtz 2005). However, more than this, social-scientific accounts of activism often valorise those actions which are unequivocally iconic, purpose-ful and meaning-ful (Thrift 1997, 2000) perhaps especially where those meanings are of a kind cultivated, or cultivable, by the work of intellectuals.

iii). A tendency to orient accounts of activism around key events or actions (see also point viii), and/or around the agency of key leaders, thinkers or ideologues. Such an approach has often had the effect of problematically over-simplifying the complex, contingent contexts, temporalities and causal happenings which produce(d) such events (McCarthy and McMillan 2003), and effacing the coproductive presence of manifold (human and nonhuman) agents in affording activism in practice (Massey 2000, Wilbert 2000, Griffin 2008).

iv). A tendency to focus, almost exclusively, upon activism which is explicitly linked to broader Social Movements and/or '-isms' (see Scott 1990, della Porta and Diani 1999). This is problematic in two senses. First, those "myriad spaces of political struggles... [and] the politics of everyday spaces through which political identities constantly flow and fix" (Pile and Keith 1997 xi), but which are not explicitly linked to Social Movements, are seldom charted. Second, as Griffin (2008 92-93) suggests, this focus effectively constitutes a circumscribed conceptualisation of activism: that is, activist practices are principally understood as relevant only inasmuch as they are either microcosms of, or else aspire to become, Social Movements. It could be argued, therefore, that many chief accounts of 'activism' remain steeped in a set of idea(l)s in relation to politics (what sorts of actions count, or make a difference?) and scale ${ }^{6}$ (at what kinds of scale do things start to count as political and/or activist?).

v). A tendency to understand activism - and/or being activist - as an unconditional state: an identity, mindset, standpoint or self-aware commitment. Thus, there is a tendency to overlook the complex, ambiguous blurrings and (dis)connections between any individual's 'activism' and everyday life (as critiqued by Brown 2007, Pickerill and Chatterton 2006) - and indeed to assume and sustain this 'between', despite efforts to move beyond this position (Anderson, 2004, Askins, this issue). Thus, moreover, this tendency has arguably essentialised and simplified the 'identity' of 'activist' and constituted some problematically circumscribed understandings of the relationship between individuals' 'identity' (e.g. their 'gender', 'ethnicity', 'sexuality', 'class') and their 'activism'.

vi). A tendency to (re)produce a particular understanding of power, a particular version of resistance and, therefore, a particular politics. Social scientists' apparent penchant for over-simple assumptions about political power and resistance - most often manifest as an implicit model of "'resistance' in implacable opposition to "power" (Pile 1997 1) - has been oft-critiqued. Yet this charge of an "implicit David versus Goliath romanticism" in social-scientific accounts - wherein "everything has

\footnotetext{
${ }^{6}$ See also Pile (1991) on the spatial metaphorics (e.g. 'outside', 'autonomy') which recur in Social Scientists' narratives of activism. We suggest that - often foregrounding autonomous spaces of/for radicalism and opposition 'outside'/'beyond' the 'mainstream' or 'hegemony' - such accounts can have the effect of detaching activism from more commonplace, less remarkable kinds of everyday milieus.
} 
to be forced into the dichotomy of resistance or submission" (Thrift 1997 124) remains resonant in relation to many chief accounts of activism. A related habit is a tendency to be cautious, and somewhat exclusionary, in delimiting what counts as resistance or activism. As Pile (1997 14-15) suggests,

"[p]otentially, the list of acts of resistance is endless - everything from foot-dragging to walking, from sit-ins to outings, from chaining oneself up in tree-tops to dancing the night away, [etc, etc]... Here, of course, lies a problem: if resistance can be found in the tiniest act a single look, a scratch in a desk - then how is resistance to be identified as a distinctive practice?" (our parentheses).

Pile (1997) and Thrift (1997, 2000) suggest that many social scientists have tended to reconcile this latter problem by implicitly limiting considerations of 'resistance' to those forms of deliberate, agentic activism which (most often as part of a Social Movement) explicitly address major, unequivocal contemporary societal ills. But surely, they imply, there is more to activism - and there are more kinds of activism - than this? For example, in their discussion of women's activism, Martin et al. (2007) provide several indications that there are. They discuss how what we term 'implicit activisms' in this paper are fostered (sometimes unintentionally) via contingent, everyday practices that often - at first glance - look little like either oppositional kinds of resistance, or deliberate, agentic activism.

vii). A tendency to take for granted a particular notion of agency. Fundamental to many accounts of activism is a particular, and rather muscular, idea(1) of activist agency: that is, activism is assumed to be an active, self-aware, straightforwardly intentional act towards a particular end (as critiqued by Ward 2007, Flam 2005). A particular, somewhat instrumental, conceptualisation of emotion is often central to this agency and sense of purpose: it is common to read of emotions as straightforward 'prompts' for action, or as 'tools' or 'resources' to be used, or acted upon, by activists. Common understandings of the roles of emotions in activism seem to us pivotal to social-scientific encounters with activism. Whilst only afforded recent attention, the particular narratives attached to emotions usher three critical reflections upon accounts of activism - the implications of which we develop in the concluding sections of this paper.

First, surely, many of these accounts are often at odds with the real, banal, messy, faltering ways in which activism happens - and the real, banal, ambivalent and emotional vicissitudes of activists' lives - in practice? Second, moreover, all this does a disservice to the emotional happenings, experiences and milieus that are constitutive of activism yet exceed the directed, cognisable, intentional 'work' that representations, identities, Social Movements and - especially - emotions are set to do. Third, some kind of causal dialectic is retained despite talk of the blurring of 'activism' with 'everyday lives' which are 'outside' activism (see especially Anderson, 2004). The turn to emotion reinforces or reinstates this dialectical relationship: this turn evokes either those feelings which must be overtly mobilised in order for activism to progress (Hercus 1999); or, this turn entails the identification of emotions that accompany or flow from activism (Wettergren 2005). Some accounts successfully scramble the causality of this dialectic by accessing both of these understandings of emotion, and by complicating the instrumentality of emotional 'work' by following the creative or ludic elements of activist events (Chatterton 2006, Pickerill and Chatterton 2006, Brown 2007, Gibson-Graham 2008).

Yet, we are not sure that even the latter can adequately explain the banality and incoherent intentionality of activism that proceeds with 'not too much fuss'. We are also not sure whether they can attend to the types of 'activisms' that emerge neither 'autonomously' from, nor at the 'interstices' of, nor at the 'boundaries' of, but simply from within the social spaces of a post-Welfarist, neo-liberal State. The distribution and organisation of Sure Start Centres would be just one geographical 
expression of that political philosophy in the UK. Indeed, as we go on to suggest in the next section of the paper, the emotional lives of a Sure Start Centre in the East Midlands, UK sometimes - just sometimes - seemed to border upon activist dispositions. These lives require a move from a 'blurring' of 'activist' and 'non-activist' categories to a position where one is not quite sure whether one is witnessing activism at all, and/or where such modest activisms are an unanticipated, emergent, property of emotive geographies of encounter.

\section{Summer, 2005: Part II}

This section of the paper represents one attempt to bear witness to the emergence of activist dispositions with/in the emotional lives of the Sure Start Centre. We conceive such dispositions as more-or-less ephemeral, temporary expressions of something supplementary to the modes of care, encounter and feeling about the Centre, climaxing at around the time of our evaluation. As a means of accessing such expressions (see also Jupp, 2007), our narrative is analytically grouped via three predominant ways in which Sure Start users ${ }^{7}$ articulated their experiences of the Centre: (i) the Centre's 'life-changing' capacity; (ii) the small, embodied practices which tangibly promulgated this capacity in situ; (iii) the ways of describing implicitly activist tendencies therein. Our narrative is intended to contextualise those expressions rather than assert any temporal or causal progression from emotion to activism or vice-versa.

\section{"It has been life-changing": caring and/for the Sure Start Centre}

Sure Start Centre users were asked to characterise their relationship with the Sure Start Centre. They provided summary descriptions that emphasised the emotional states and changes noted in both their own lives, and those of other mothers encountered at the Centre.

"Sometimes I get down and I feel really stuck - like I feel totally on my own. But I come here and I feel OK again - I feel like I'm quite normal after all"

"I'm definitely happier, less isolated, more involved. When you first have a child it is very hard. You just sit at home and you feel totally at a loss. But coming to Sure Start gives you everything you need. [drop-in worker] comes over and makes you welcome and everyone chips in to help you out, and suddenly things don't seem so bad"

"Now, I talk to more people. It gives me a chance to get out of the house, something to look forward to. With not having family and friends in the area, it was nice to talk to someone instead of crying my eyes out. So yes I feel less isolated"

"It doesn't matter if its rain, snow or a howling wind outside, you know that there is always someone here to help. Sure Start is a friend, really - I'd call it a friend"

Respondents emphasised that modes of feeling - respectively 'normal', 'at a loss', 'happier', 'welcome', 'less isolated' - best characterised their experiences of using the Centre. Many recounted the emotional changes they had undergone. Most identified a shift from emptiness, stress, anxiety and sadness to warmth, happiness and opportunity. Significantly, these emotional gains were commonly accompanied by a gradual move from 'isolation' to sociality - or feeling 'accepted' or 'involved'.

\footnotetext{
${ }^{7}$ Hereafter, we refer to research participants as 'mothers' as all but one of the 150 respondents were mothers with young children.
} 
Sure Start users seemed to be making an implicit normative judgment that being accepted or involved was a tangible, positive outcome for themselves and their families. Not coincidentally, overcoming family members' withdrawal from extra-familial relationships is one of the key objectives of Sure Start's work. Yet, interviewees provided a sense of exactly how their involvement mattered in the context of their lives - both in terms of emotional changes and the material differences to the everyday lives and relationships with others.

Many Sure Start users were so deeply affected by their experiences of using the Centre that they insisted upon its 'life-changing' benefits for them.

"It has been life-changing in the last couple of years. I walk down the street now doing the shopping and I see people to say hello to. It's like an extended family"

"I'm not exaggerating - this place has turned my life around"

"It is a lifeline. When I realised the stuff I could do and all the stuff that was available, it opened up a whole new direction for me - it was like a whole new world. Things weren't bleak any more - I was like 'oh my god - look at all the things I can do,$"$

Whilst articulating such change, some mothers began to elucidate a sense of an opening or release afforded via their experiences of the Sure Start Centre. The Centre had radically changed their outlook on life, opening up possibilities that were both imminent and immanent - metaphorically both a life-event from which 'things weren't bleak any more', and a learning experience which revitalised the spaces of the local community such that 'doing the shopping' had become a positive, sociable activity.

\section{“All you can do is get the kettle on": small acts, kind words}

The emotional changes recorded above designate the Sure Start Centre as a kind of experience, event or moment in mothers' lifecourses. The emotional relationships forged with - and from - the Centre were critical to these changes. However, the materials, practices and spaces within the Centre remain obscured in these narratives. We therefore asked respondents to consider the details which, taken together, constituted the major emotional changes they reported. Evidently, the 'life-changing' milieu of the Sure Start Centre was importantly constituted out of 'getting the kettle on', arms around shoulders, having chats, making sandwiches, washing up, and so on.

"There's always someone worse off. You see it all the time - people in a right state when they come [to the Sure Start Centre for the first time]. All you can do is get the kettle on and put your arm around them"

"You just sit and have a chat really - make the sandwiches together and wash the cups [for the children's frequent drinks of fruit juice]"

"We sit and have a natter. We talk about what's been going on, and who's done what, and last night's TV"

In keeping with a number of geographers, we are keen to emphasise the significance of such banal acts to people's lives, and especially to the types of caring performed at places like the Sure Start Centre (Parr 2003, Kraftl 2006, Popke 2006, Laurier and Philo 2006, Horton and Kraftl 2006, Kraftl and Horton 2007, cf. Valentine 2008). The quotations above represent three of hundreds which emphasised the multiple, material details, successes, advice, and acts which constituted the Centre's 
work. Indeed, for many mothers, such details were central to the Centre's success and were - for some who were 'worse off' - all that was really left. In some cases, small successes corresponded with the measurable outcomes on which the Centre is formally evaluated - using a cup being exemplary of a child's learning (cf. NESS 2005b). In others, simple and particularly British acts - like making a cup of tea - signify a disposition for caring whose functioning supplemented the more formal goals of the Sure Start scheme.

In their discussions, mothers constructed rich images of the manifold details that mattered, fundamentally, to their engagements with Sure Start. In doing this through the interviews, they also effected more general characterisations of the Centre as a 'caring' environment.

"I was really nervous when I first came. I'm not good coming to new places and meeting new people, but when I first came through the door, [drop-in worker] couldn't have made me feel more welcome. If it wasn't for her, I probably wouldn't have had the bottle to keep coming"

All the support you get here is wonderful. If I've had a terrible weekend and I need a shoulder to cry on I know I can come here and get empathy. It is very easy going here. Everyone is sympathetic and supportive. At other places I've been to, I feel judged - I go and I can tell that they are watching me and judging me and my parenting"

"I like the attitude of the staff, and the continuity. There's more mature staff, and they add a sort of homely atmosphere. It is inspiring to see their homeliness and dedication. And the continuity is good. When you see people who start out coming along, and they go and become parent reps and everything, and some even become staff. That is really good"

Rather than a singular model or descriptor for care, the three quotes above exemplify the many ways in which the Centre provides a supportive environment. Certain key terms stand out: 'welcome'; 'support'; 'empathy'; 'sympathy'; 'homely atmosphere'; 'continuity'. The Centre does not merely provide 'care', to be experienced as a homogeneous product. Rather, as a space, the Centre collects and is constituted by sets of caring practices which are variously orientated around particular affective dispositions - welcome, empathy, home, etcetera. Respondents did not merely witness the banal details of everyday life and care at a Sure Start Centre. In addition, they characterised the intentional manipulation of inter-personal relations, dispositions, affects and atmospheres by Sure Start personnel and, in time, other parents (cf. Thrift 2004, Barnett 2008). This emotion work (Schrock et al. 2004) did present multiple versions of caring, but also precipitated many other outcomes. In the three preceding quotations, those outcomes were, most notably, continued engagement with the Centre, non-judgemental advice, and the eventual recruitment of some parents as carers. Mothers noted that each of these outcomes was a 'good' thing. 


\section{Interval: Conceiving activism}

We suggest that mothers' narratives about the Sure Start Centre - combining banal details with affective dispositions - provided for them an appropriate explanatory frame for the sometimes enormous emotional changes they had experienced. Similarly, their accounts explained the intense relationships that mothers forged with the Centre, its staff, and other parents. But the story does not end here. For the crux of our argument is that amidst all of these events and narratives - somehow, somewhere, at some moment - something resembling 'activism' emerged. Three sets of quotations in the next section of the paper represent this something resembling activism at the Sure Start Centre.

We want to signpost here that we conceive of this emergent activism in two ways, which we discuss fully in the paper's conclusion. First, we suggest that discrete activist mindsets, dispositions, events, places, acts or identities did emerge, albeit unintentionally, from the emotive relations depicted earlier in the paper. In so doing, we complicate the linear causality of accounts of activism which either explain activism as the knowing, desired goal of some particular emotion (usually anger), or which follow the emotions which, latterly, come to be associated with doing activism. Second, though, we critically reflect upon the residual linearity and causality which our own notion of 'emergence' presupposes. We do so by presenting a series of 'activisms' which are thoroughly suffused with the very same emotive, affective dispositions which seem, at first glance, to offer a causal explanation for those activisms. Rather, activisms are understood here as imperceptible mo(ve)ments of modestly political intent, as tiny, ongoing modulations between caring and some kind of temporary supplement: 'implicit activisms'.

\section{Summer, 2005: Part III}

\section{'Activism' I: reaching out}

Respondents were asked to reflect upon the reasons that many families (again, designated as 'Mums') did not use the Sure Start Centre. Whilst their answers varied from cultural differences to ignorance, the details of their reasoning need not detain us here. Instead, we are concerned with the solutions that mothers forwarded to under-utilisation of the Centre by eligible families. Many centred on a desire to 'reach out' to others locally.

"I know a lot of people on [the estate], who you think 'there's so much more you could be doing - you'd think [Sure Start] was brilliant'. Sometimes I think I should go and grab them and hand them over to [Sure Start worker]!"

"Being here and seeing the difference it makes, it makes you want to help reach out to more people who need a bit of a helping hand"

"There are so many mums and kids on the estate who should be down here. Sure Start need to get their act together a bit and try to get them down here, really... We [Sure Start users] could help if they let us"

The consistent grammatical inflection of these quotations is striking. Each statement of intent is qualified by the conditional 'could' or 'should', signalling that, at the time of speaking, none of these mothers had acted upon their intentions. Speaking from their own - and other mothers' - emotive relationships with the Centre, they identify the types of 'mums' who in their minds would benefit from similar experiences. On the basis of this reflection, each speaker discerns that they could or should 'grab them' or 'drag them in here'. But they do not - yet - feel empowered enough (by the Centre) to act on the basis of these feelings, and so those feelings remain statements of intent. There 
is, we suggest, a kind of banal activist disposition here that signifies a minor degree of socio-political efficacy at play - the simple intent to exert some agency, momentarily, over just a handful of others, to a very specific end set firmly within the parameters of everyday lives in 'mainstream' postWelfarist Great Britain. Theirs was a conditional activist disposition writ small; but, for those mothers, the stakes of engaging with the Sure Start Centre - in the contexts of their lives - could perhaps not have been higher.

Although evident in relation to non-users of the Centre, this particular, conditional disposition towards activism was displayed in other contexts. For instance, many interviewees argued that needy families outside the area served by the Sure Start Centre - delineated using UK postal code data were unfairly excluded from using the Centre.

"If there's one thing I don't like, it's the postcode thing. It's not fair to exclude people like that"

"The worst thing about Sure Start is the [postcode] boundary. I know people who are in a much worse position than me, but they're not entitled to come here just because of their house number, and that doesn't seem right. It's not fair"

We suggest that sentiments such as these - and indeed those surrounding non-users - represent modest activist dispositions in two senses. First, they evoke the kinds of emotions and moral subject positions that are integral to many kinds of activism (Flam 2005). In particular, anger - or, more accurately, frustration - is mobilised in order to highlight the injustices inherent to both Sure Start Policy and mothers' self-exclusion from the Centre. Second, respondents displayed a self-reflexive awareness of the contexts for their own, emotive, engagements with Sure Start. Although they commented upon particular socio-cultural constraints in a highly localised sense, they were able to extrapolate from their own experiences a set of moral-political reflections about 'other' families living nearby.

We accept that many of these reflections were shared by many mothers, and were learned through discussions with staff and other parents. More importantly, though, we argue that these senses of activism do not simply represent anticipatory knowledges or emotions for a more vital, identifiable, 'active' activism somewhere in the future. The kinds of emotionally-charged positions presented above did not entail any assured progression towards any other or greater style of activist practice. In most cases mothers spoke in a self-consciously conditional, an-active manner which narrated an activist tendency or feeling which was not totally in-active (the tendency did exist), but which, in effect, did little more than represent a collective inclination towards frustration and an implicit feeling that something should/could be done. We therefore posit that it would be accurate to acknowledge that something politically meaningful - albeit modest - is being depicted in these inclinations. And this something we would like to tentatively label as a kind of activist disposition.

\section{'Activism' II: responding to the threat of closure}

As we undertook our research, the threat of the closure of the Sure Start Centre loomed large. 'Uncertainty' at the Centre was becoming manifest in plans - or, indeed, rumoured plans - to remove or rationalise its provision. Within this context, a very different kind of activism from that in the previous section emerged - albeit similarly entrenched in the emotional, affective relations that constituted the Centre for its users.

In direct response to questions about the Centre's closure, the majority of mothers formulated impassioned pleas characterised by shock, emotional loss and disorientation. 
"Oh my word. We are like one family together. I'd be devastated to be honest with you”

"I don't know what I would have done if I had grown up in a place that didn't have this. It's scary to even think"

"I'd be bored, lost, mental. There'll be nowhere to go"

"A lot of people would be wandering around, not knowing what to do - they'd be overwhelmed"

"It would be catastrophic on a personal level"

"I'd lose all the advice that they give me. All that knowledge. It is great to know that you can come and they really know what they are talking about. And they really explain things in a good way - like the talk on the same level as you"

Superficially, these quotations reiterate the emotional connections that mothers had forged with the Sure Start Centre. Indeed, the possible loss of the Centre stimulated a range of negative emotions, associated with fear, persona/emotional loss, boredom, catastrophe and a loss of empathy. They reiterated how the Sure Start Centre mattered to them most in these terms. Less commonly, though, respondents cited particular, pragmatic challenges that the closure of the Centre would cause them. All of these reasons were geographically-inflected, citing the Sure Start Centre as a local service, and as a stimulus for their sense of sociability within the community:

"I would miss everything. I have met so many people and friends. If I need any help I go to the Sure Start. This is the only place I know as I am quite new to [town]"

"I would miss getting out of the house and having some adult company and advice"

"This is ideal because it is on the door step. We would have to pay loads to go anywhere else"

"I'd just be stuck at home all day. There is the Mums \& Tots in the community centre, but it's only on one morning and one afternoon per week. Plus you have to pay"

It transpired that even amongst such pragmatic concerns as paying for childcare, it was the emotional impact that mattered most in the context of the Centre's possible closure. We want to carefully suggest that mothers' concerns indicate a blurry relationship between emotion and activism which is perhaps only implicit and virtually imperceptible. Read as responses to an interview question, Sure Start Centres users' passionate pleas could be interpreted as knowing strategies, designed to emphasise to an external audience why the Centre should remain open. Thus, they chose to concentrate on knowingly affecting statements that would effect a favourable outcome.

Yet, we would also observe that it would be overly instrumental and cynical to conclude that respondents emphasised emotions for purely strategic purposes. They did not simply or always deploy emotions strategically, nor simply or always to highlight 'genuine' emotional responses. They did either, both, and more besides. Hence, we posit a blurriness between emotion and strategic action (and activism) whose banality and particularity does not merely query the distinction between emotion-for-emotion (in/of everyday lives) and emotion-for-strategy's sake (emotional 'work'). Instead, and moreover, the indistinct causality between activism/emotion and the ceaseless implication of this couplet with/in mothers' ongoing lives at Sure Start renders a decisive explanation 
or definition of 'activism' a difficult task, (re)interrogating in this context at least what activism means.

Activism III: so, what now?

Once we had discussed the possible closure of the Centre, many respondents outlined how they would (seek to) become involved in its defence. They revisited the kinds of conditional activist dispositions that had characterised their attitudes to non-users, whilst emphasising that the sense of emotional solidarity fostered at the Centre was at the heart of 'standing up for themselves':

"We look out for each other, so if anything bad happened I think we'd give someone a right earful!... If they took this away, a lot of people would be up in arms!"

"I haven't really got the time to be a parent rep[resentative], but if it was something serious, like if they started seriously talking about closing this place down, I think we'd stand up for ourselves"

"I haven't had anything to do with that side of things, but if there was a big issue, I think most of the mums here would be up for it. We stick together like that"

In each case, the use of the word 'would' is indicative not only of the possible closure of the Centre, but the reticence of mothers to commit to anything more than being 'up in arms'. It was not clear how, when or where they would 'stand up for themselves'. This is far from a slur upon their moral convictions; rather, respondents themselves suggested that they did not feel sufficiently empowered or knowledgable - in Pierre Bourdieu's over-used terms, they did not obtain the necessary cultural capital - to translate their activist sentiments into any kind of overt, public, activist practice.

"You've heard the rumours [about the Centre closing] - we'd get involved, if they [Centre staff] told us what to do"

"There have been meetings [with staff from the whole area] about all the problems, but they are tedious and we do not feel part of it... There should be better training for users who attend meetings, because at the moment you have the situation where we attend meetings but don't participate. We don't say anything... because the people in the meeting are so experienced, so it is a bit intimidating to go into that environment... We want to help out, but they've got to change the way they do the large meetings"

These two latter quotations are revealing. Many respondents felt that they would follow directions from staff regarding any defence of the Centre. Much of their anxiety about doing or being more than 'users who attend meetings' was a function of their confidence at participating in large meetings. As mentioned above, mothers' activist leanings draw upon Centre staff for both information and direction - they feel they need to be 'told what to do' (see also Woodsworth, this issue). Yet their reliance was not specifically upon the institutional culture of Sure Start. For mothers and front line Sure Start workers articulated an antagonism with the paternalism of Sure Start managers - who dominated the meetings depicted above. Mothers and front-line workers both felt disenfranchised in this way, and felt they could become allied with each other. Front-line workers could provide resources for activism and enable the kinds of solidarities desired by mothers - but they did so beyond the bounds of official Sure Start policies favoured by managers. 
We are also persuaded that - whether or not these specific, named difficulties are overcome - the styles of activism experienced by individuals like Sure Start users are constrained by multiple manifestations of (working) classed and gendered assumptions. This effect is also likely generational (in the UK context at least). Although often effaced, Spence and Stephenson (2007) document the key, ongoing role of women in both emotional and political activisms during UK miners' strikes in the 1980s. Overwhelmingly, working-class women in contemporary UK society would probably not share the same kinds dispositions or social ties as those during the 1980s. Certainly, the idea of overt activism would have been unintuitive and uncomfortable - or even alien and antagonistic - to the lives of most of the individuals quoted in this paper, as would be the case for many mothers living in one of the most socio-economically deprived areas of the United Kingdom. Even if not, the means to achieve activism (certainly, the version of activism most often valorised by social scientists) are often found elsewhere: commonly, amongst Social Movements and counter-cultures with a significant university-educated, middle-class membership. Rather than a definitive structuring mechanism, though, we simply assert that these are discourses surrounding class and public service provision which reduce (or, better, reconfigure) the opportunities for activist intervention when compared with the configurings of constraints and opportunities available to more recognised activists, including 'subaltern' groups from outside the West, who have become increasingly integrated with Western activist groups and cultural resources (cf. Featherstone 2003, Routledge 2003). Should this generalisation be uncomfortable, it should be remembered that these mothers were effectively striving for activism within - not at the interstices of, or in opposition to - contemporary post-Welfarist neoliberalism in the UK. To be clear: other activists are equally or perhaps more greatly disenfranchised than many Sure Start users; yet the resources and assumptions upon which they draw are sufficiently different that their forms of activism can more readily be expressed as activist.

Finally, a minority of respondents complicated the picture still further by suggesting that they had become or intended to become involved in discrete activities:

"I would like to get more involved because of everything that they have done for us. I definitely want to be involved, I have already started with fundraising and I want to do more, if they'll let me. It is important to give something back... We've got to make sure this place is still here"

"A few of us had the idea that we could help with fundraising if things got bad. We need to be thinking a bit smart about how we can get additional money. We need to be thinking about funding and fundraising"

"I want to be a parent rep - I feel up for that sort of responsibility now. I think it is brilliant how they give you the confidence to do things with your life, and I want to give something back"

All of the cited activities centred either around fundraising or becoming a parent representative; on the latter action, it is worth remembering that some users had representatives prior to the research and a couple had become formal staff at the Centre. It may be that these activities are controllable, 'legitimate' outlets that Centre staff are able to provide for mothers wishing to become more involved. Notwithstanding this observation, the critical point is that two of the mothers quoted above refer once again to their emotional attachment to the Centre - to 'everything that they have done for us' and 'how they give you the confidence to do things with your life'. These discrete modes of activism proceed with 'not too much fuss': they are still constrained, still modest, and still, largely, implicit. They are also - and this hardly needs reiterating now - thoroughly enmeshed in the emotional, affective, material relationships that constitute the Sure Start Centre. 


\section{Conclusion: implicit activisms?}

Our interest throughout this paper has been in kinds of practice which could be construed as activism, but which differ quite markedly from the kinds of activism which have most often captured the imaginations of social scientists. Despite the multiplicitous styles these former kinds of activisms take (see below), we wish to call them collectively 'implicit activisms'. These are activisms which are politicised, affirmative and potentially transformative, but which are modest, quotidian, and proceed with little fanfare. They operate on the border not ontologically between activism and 'non'-activism as identity or practice/praxis (Anderson 2004), but on the border between what - epistemologically comes to be called activism. One of the contributions of this paper is to acknowledge and begin the task of understanding implicit activisms.

Earlier, we posited two ways to theorise the relationship between emotion and activism through mothers' experiences of the Sure Start Centre. First, we suggested that discrete activist mindsets, dispositions, events, places, acts or identities emerged from the emotive experiences that constituted the Centre. Second, we argued the need to critically reflect upon the residual linearity and causality which this notion of 'emergence' presupposes. Hence, implicit activisms are also understood as imperceptible mo(ve)ments of modestly political intent, a kind of ephemeral supplement. Mothers' reflections upon the Sure Start Centre addressed its emotional significance, its banal-material practices of caring, its non-users, and its uncertain future. Taken together, they comprise a set of conjoined discourses that narrate multiple relationships between emotion and activism. In particular, Sure Start 'activism' was galvanised and made visible by the threat of closure but the affective/everyday bonds of care (notably for one another) and caring (e.g. about whether the Centre continues) preceded and outlasted this particular threat of closure. These discourses de-centre the spectacular, vitalist, confidently knowing activisms aligned with the feminist, environmental, anti-war and queer movements (amongst others), notwithstanding their multiply-constituted relationships with the everyday. Critically - and perhaps not uncontroversially - the kinds of spaces, practices and knowledges typical of the Sure Start Centre would be the everyday against which activisms are typically figured; or they are the everyday which goes completely unwritten in accounts of the 'everyday' of activism which privilege autonomous practices such as communal cooking.

In closing, we want to complicate our two-fold theorisation of the relationship between emotion and activism by - tentatively - sketching a conceptual framework for further forays into implicit activisms. From our empirical analysis and critical reading of activist literatures, we discern seven styles or modes of being which distinguish implicit activisms of the kind witnessed in this paper from those more commonly cited by social scientists. In so doing, we seek to emphasise the differences between 'implicit activisms' and 'other activisms'; but this schema is not to be read as a totalising attempt to foreclose alternative explanations of activism. The following points are one way in to the messiness of implicit activisms - not a way out.

First, implicit activisms are often modest. In distinction to 'glamorous' or spectacular forms of activism (Pile and Keith 1997, Carter 2005), the moments and movements entailed in reaching out to non-users of the Sure Start Centre are virtually indistinguishable from the types of caring that proceed at the Centre on a daily basis. The kinds of 'activism' witnessed in this paper proceeded in a selfconscious, self-doubtful, hesitant, perhaps-circumscribed manner: with, complicatedly, 'not too much fuss'. Whilst activist literatures acknowledge more banal practices within more recognisable activisms (Griffin 2005, Chatterton 2006), they do not necessarily acknowledge the banal activisms momentarily and modestly enmeshed in everyday lives.

Second, implicit activisms often leave little (representational) trace. This observation does not simply require an acknowledgment of the nonrepresentational geographies of activism - a task 
already ably begun elsewhere (Chatterton 2006, Brown, 2007). Rather, in comparison with the kinds of overtly symbolic, meaningful and self-conscious traces left by many activisms, Sure Start activisms left virtually no mark - visual, textual or otherwise. These were single-issue activisms directed towards the ongoing work of a public service, and hence pragmatic interventions that did not seek to leave behind anything supplementary to the continued functioning of the Centre. Indeed, in many instances, Sure Start users recorded activist dispositions which remained feelings and tendencies whose conditionality (see below) both exceeded and did not-yet warrant representation.

Third, implicit activisms are often non-totemic. Many accounts of activism are orientated around 'key' figures: events, thinkers or actions (see, for instance, Zeilig and Ansell 2008). Contrastingly, Sure Start activisms did not (yet) organise themselves around any 'key' figures or leaders (see also Woodsworth, this issue). In formulating activist dispositions, Sure Start users drew instead on heterogeneous collectives of discourses, practices and affects - especially diverse practices of care and welcome. The 'actions' - if there were any to speak of - consisted of multiple, conditional subject positions that recognised that 'something should be done'.

Fourth, implicit activisms are often tenuously connected to philosophical positions (or-isms). Most activisms are connected to social movements with recognisable philosophical or moral positions such as feminism or environmentalism (for a fuller list, see Crossley 2002 1). Certainly, Sure Start activisms retained a keen focus upon particular issues - namely the provision of family support and care. However, quite simply, they were neither explicitly nor knowingly connected with any broader philosophical position. On the one hand, Sure Start activisms were emergent from disparate experiences, emotions and inter-personal relationships - if anything, these heterogeneous practices of care were the 'position' from which any activism was begun. On the other - and anecdotally - many staff members and users told us they were actively antagonistic to one '-ism' that has not been mentioned in the body of this paper: feminism. Hence, whilst the analysis above might compare with feminist analyses of activism (Hercus 1999) and childcare (Holloway 1998), we would be very cautious to align Sure Start activisms with feminism in any but a tenuous sense.

Fifth, implicit activisms do not often constitute an identity. Whilst recognising that much socialscientific work has deconstructed the 'activist'/'other' binary, much of the same work rightly retains a commitment that some kinds of 'activist' identities do - if only temporarily - exist (especially Anderson, 2004). The kinds of implicit, ephemeral activisms at Sure Start displayed virtually no commitment to a particular activist identity. Whilst some mothers recognised that they would 'stick together', such expressions of solidarity were very low-key: being a 'Sure Start Mum' was far less important than the emotional changes and familial support that did affect/effect certain activist dispositions.

Sixth, implicit activisms often scramble the power relations involved in activism. Whilst many social-scientific accounts of activism focus upon interrogating (or dismantling) the power/resistance couplet, the absence of any overt, active kinds of resistance at Sure Start demands an exploration of what else might be constituted by activism vis-à-vis 'power'. We would suggest doing something more (or, rather, much, much less) than assert the multiplicity of resistance (Featherstone 2003), or the significance of overtly autonomous practices (Pickerill and Chatterton 2006) - although both represent alternatives to the power/resistance dualism. Rather, Sure Start activisms address minor, banal issues (which still matter) via activist dispositions that do not seek to significantly challenge power relations but to find small, pragmatic steps to engage non-users, raise money, or simply continue as normal. Critically, this continues within, and does not seek to challenge, the socioeconomic relations of post-Welfarist neo-liberal public service provision. 
Seventh, implicit activisms are often conditional. Activism is traditionally viewed as a straightforwardly intentional act directed towards a particular end. Understood in this way, emotions either become resources for activism, or conceived as more-or-less significant components of activism-in-practice. Yet, we are not sure that it is always so easy to discern precisely where activism comes from, and ends. Whilst many social scientists have blurred the boundaries between activism and 'everything else', these discussions are confined to how particular sets of philosophies, actions, identities and symbols interact with and blur with the 'non-activist'. Yet they do not yet broaden their horizons to the manifold 'non-activisms' that contain banal, temporary, contingent flickerings of activist intent, operating in effect beyond the activism/everyday life dialectic. Sure Start users witnessed these latter kinds of activism in two ways. One, in detailing activist dispositions and tendencies which were no more than that - conditional, sketchy recognitions that they 'should' or 'could' support the Centre in response to its possible closure. Two, in accounting for the suffusion of such tendencies within the emotional relationships and affective atmospheres promulgated at the Centre. Rather than 'emerge' from such emotional states, mothers' activist tendencies were conditionally co-implicated in the sheer work (and angst) involved in ensuring the Sure Start Centre held together.

The question of how to mobilise such conditional dispositions and emotions - indeed, as to what resources (educational, financial, social) might be needed to enact or 'force' a link between implicit activist dispositions and more knowable forms of activism - is an open one, and perhaps too programmatic given the course of our discussion above. We can only hint at an answer here, based upon our empirical evidence. In one sense, it seemed that Sure Start users needed a kind of 'push' from Sure Start Centre workers (not forgetting that some mothers had themselves become workers), or from the possible, imminent closure of the Centre. In another, perhaps more significant sense, the link was more contingent: activism emerged from a growing, collective sense that the emotional support provided by the Centre was under-utilised and that something had to be done about it. Clearly, that sense of something was thrown into more sharp relief by the possible closure of the Centre - it may be that without such a particular threat, any kind of activism may have remained conditional (and hence some other kind of resource, or push, might have been necessary) - although this take us into the realms of hypothesising about alternative outcomes to the story presented above.

With these seven points, and this last hint at a pragmatic conclusion, we do not seek to mark out any 'other' practices, places, dispositions or emotions beyond the Sure Start Centre as 'implicit activisms'. Rather, we call simply for social scientists - and activists - to consider the seven suggestions above as possible points of departure for broadening the debate about what constitutes activism - and what activism can do.

\section{Postscript: Summer, 2008}

The Sure Start Centre remains open for business. Its latest OfSTED (2008) report describes the Centre as 'outstanding'; the contribution made by parents/carers to the Centre's development and sustainability is also described as 'outstanding'. Of the people interviewed in this paper: one sits on the management Board of the Sure Start Centre; others have set up support group for local women with Post-Natal Depression; another has taken a qualification in hairdressing and puts on 'Ann Summers' parties (both services being well-used by friends from the Centre); another 'did a runner' and fled an abusive husband...

Meanwhile, life at the Sure Start Centre goes on and on. Each morning, at 8am, a new day begins: the doors are unbolted; the kettle is boiled; toys and crayons and paints are arranged on the 'play-mats'; a box of tissues is placed on the kitchen table... 


\section{Acknowledgments}

Thanks are due to Chris Durkin, Sue Kennedy and Ruchira Leisten, who worked on the evaluative project reported in this paper. We also gratefully acknowledge the generous support given to the project by the staff and users of the Sure Start Centre. Finally, thanks to Jenny and Gavin for providing the opportunity to contribute to this special issue, and to two anonymous reviewers for their helpful comments on an earlier version of this paper.

\section{References}

Anderson, J. 2004. The ties that bind? Self- and place- identity in environmental direction action. Ethics, Place and Environment 7: 45-57.

Barnett, C. 2008. Political affects in public space: normative blind spots in non-representational ontologies. Transactions of the Institute of British Geographers 33: 186-200

Belsky, J., Melhuish, E., Barnes, J., Leyland, A. and Romaniuk, H. 2006. Effects of Sure Start local programmes on children and families: Early findings from a quasi-experimental, cross sectional study. British Medical Journal 332: 1476-1482.

Belsky, J., Barnes, J. and Meluish, E. 2007. The National Evaluation of Sure Start. Bristol: The Policy Press.

Brown, G. 2007. Mutinous eruptions: Autonomous spaces of radical queer activism. Environment and Planning A 39: 2685-2698.

Cameron, D. 2006. The importance of family life. Speech to National Family and Parenting Institute, June $21^{\text {st }}$ 2006. http://www.conservatives.com/tile.do?def=news.story.page\&obj_id=130523

Carter, A. 2005. Direct action and democracy today. Cambridge: Polity Press.

Chatterton, P. 2006. 'Give up activism' and change the world in unknown ways: Or, learning to walk with others on uncommon ground. Antipode 38: 259-281.

Cohen, B., Moss, P., Petrie, P. and Wallace, J. 2004. A new deal for children? Re-forming education and care in England, Scotland and Sweden. Bristol: Policy Press.

Crossley, N. 2002. Making sense of social movements. Milton Keynes: OUP.

della Porta, D. and Diani, M. 1999. Social movements: An introduction. Oxford: Blackwell.

Featherstone, D. 2003. Spatialities of transnational resistance to globalisation: The maps of grievance of the Inter-Continental Caravan. Transactions of the Institute of British Geographers 28: 404-421.

Flam, H. 2005. Emotions' map: A research agenda. In Emotions and social movements. Ed. H. Flam and D. King. London: Routledge.

Gibson-Graham, J.K. 2008. Diverse economies: Performative practices for 'other worlds'. Progress in Human Geography published online early.

Glass, N. 1999. Sure Start: The development of an early intervention programme for young children in the United Kingdom. Children and Society 13: 257-264.

Griffin, C. 2005. Social conflict and control in Hanoverian and Victorian England. Journal of Historical Geography 31: 168-176.

Griffin, C. 2006. Knowable geographies? The reporting of incendiarism in the eighteenth- and early nineteenth century English provincial press. Journal of Historical Geography 32: 38-56

Griffin, C. 2008. Protest practice and (tree) cultures of conflict: Understanding the spaces of 'tree maiming' in eighteenth- and early nineteenth-century England. Transactions of the Institute of British Geographers 40: 91-108.

Gustafsson, U. and Driver, S. 2005. Parents, power and public participation: Sure Start, an experiment in New Labour governance. Social Policy and Administration 39: 528-543.

Hercus, C. 1999. Identity, emotion and feminist collective action. Gender \& Society 13: 34-55.

HM Treasury (2000) Spending review 2000. London: HM Treasury.

Horton, J. and Kraftl, P. 2006. Not just growing up but going on: materials, spacings, bodies, situations.

Children's Geographies 4: 259-276.

Horton, J. and Kraftl, P. forthcoming. What (else) matters? Policy contexts, emotional geographies.

Environment and Planning $A$.

Jacobs, J., Cairns, S. and Strebel, I. 2007, ‘A tall storey...but, a fact just the same': The Red Road high-rise as a black box. Urban Studies 44: 609-629.

Jenks, C. 2005. Childhood. London: Routledge.

Jupp, E. 2007. The feeling of participation: everyday spaces and urban change. Geoforum 39: 331-343. 
Kraftl, P. 2006. Building an idea: The material construction of an ideal childhood. Transactions of the Institute of British Geographers 31: 488-504.

Kraftl, P. 20008. Young people, hope and childhood-hope. Space and Culture 11: 81-92.

Kraftl, P. and Horton, J. 2007. 'The health event': everyday, affective politics of participation. Geoforum 38: 1012-1027.

Kurtz, H. 2005. Reflections on the iconography of environmental justice activism. Area 37: 79-88.

Latour, B. 1988. Science in Action. Boston: Harvard University Press.

Laurier, E. and Philo, C. 2006. Cold shoulders and napkins handed: Gestures of responsibility. Transactions of the Institute of British Geographers 31: 193- 208.

Lyman, S. 1995. Social theory and social movements: Society as sociodicy. In Social movements: Concepts and case studies. Ed. S. Lyman. London: MacMillann.

Martin, D., Hanson, S. and Fontaine, D. 2007. What counts as activism? The role of individuals in creating change. Women's Studies Quarterly 25: 78-94.

Massey, D. 2000. Entanglements of power: Reflections? In Entanglements of power: Geographies of domination and resistance. Ed. J. Sharp, P. Routledge, C. Philo and R. Paddison. London: Routledge.

Maxey, I (1999) Beyond Boundaries? Activism, Academia, Reflexivity and Research. Area 31: 195-198.

McCarthy, T. and McMillan, J. 2003. Introduction. In The radical reader: A documentary history. Ed. T. McCarthy and J. McMillan. New York: New Press.

NESS (National Evaluation of Sure Start). 2005a. Implementing Sure Start local programmes: An In-depth study. London: DfES Sure Start Unit.

NESS (National Evaluation of Sure Start). 2005b. National Evaluation Report: Early impacts of Sure Start local programmes on children and families. London: DfES Sure Start Unit.

Parr, H. 2003. Medical geography: care and caring. Progress in Human Geography 27: 212-221.

Pickerill, J. and Chatterton, P. 2006. Notes towards autonomous geographies: Creation, resistance and selfmanagement as survival tactics. Progress in Human Geography 30: 730-746.

Pickerill, J. and Webster, F. 2006. The anti-war/peace movement in Britain and the conditions of information war. International Relations 20: 407-423.

Pile, S. 1997. Introduction: Opposition, political identities and spaces of resistance. In Geographies of resistance. Ed. S. Pile and M. Keith. London: Routledge.

Pile, S. and Keith, M. 1997. Preface. In Geographies of resistance. Ed S. Pile and M. Keith. London: Routledge.

Popke, E.J. 2006. Geography and ethics: Everyday mediations through care and consumption. Progress in Human Geography 30: 504-512.

Routledge, P. 2003. Convergence space: Process geographies of grassroots globalization networks. Transactions of the Institute of British Geographers 28: 333-349.

Schrock, D., Holden, D. and Reid, L. 2004. Creating emotional resonance: Interpersonal emotion work and motivational framing in a transgender community. Social Problems 51: 61-81.

Scott, A. 1990. Ideology and the new social movements. London: Routledge.

Spence, J. and Stephenson, C. (2007) Female involvement in the Miner's strike 1984-85: trajectories of activism. Sociological Research Online 12: unpaginated.

Sure Start. 2000. What is Sure Start? London: DfES Sure Start Unit.

Sure Start. 2002. Sure Start: a guide for sixth wave programmes. London: DfES Sure Start Unit.

Sure Start. 2007. Sure Start Centres pass the million mark. London: DfES Sure Start Unit press release, 11/4/07.

Sure Start Centre. 2004. Local evaluation report 2003-04. East Midlands, UK: Sure Start Centre.

Sure Start Centre. 2005a. Memo: local evaluation 2005-2006. East Midlands, UK: Sure Start Centre.

Sure Start Centre. 2005b. Invitation to tender: Sure Start local evaluation 2005-2006. East Midlands, UK: Sure Start Centre.

Sure Start Centre. 2006. Development plan 2006. East Midlands, UK: Sure Start Centre.

Thrift, N. 1997. The still point: Resistance, expressive embodiment and dance. In Geographies of resistance. Ed S. Pile and M. Keith. London: Routledge.

Thrift, N. 2000. Entanglements of power: Shadows? In Entanglements of power: Geographies of domination and resistance. Ed. J. Sharp, P. Routledge, C. Philo and R. Paddison. London: Routledge.

Thrift, N. 2004. Intensities of feeling: Towards a spatial politics of affect. Geografiska Annaler Series B 86: 57 78.

Valentine, G. 1996. Angels and devils: the moral landscapes of childhood. Environment and Planning D: Society and Space 14: 581-599. 
Valentine, G. 2008. Living with difference: Reflections on geographies of encounter. Progress in Human Geography 32: 323-337.

Ward, K. 2007.Geography and public policy: Activist, participatory, and public geographies. Progress in Human Geography 31: 695-707.

Wettergren, A. 2005. Mobilisation and the moral shock: Adbusters Media Foundation. In Emotions and social movements. Ed. H. Flam and D. King. London: Routledge.

Wilbert, C. 2000. Anti-this - anti-that: resistances along a human-non-human axis. In Entanglements of power: Geographies of domination and resistance. Ed. J. Sharp, P. Routledge, C. Philo and R. Paddison. London: Routledge.

Zeilig, L. and Ansell, N. 2008. Spaces and scales of African student activism: Senegalese and Zimbabwean university students at the intersection of campus, nation and globe. Antipode 40: 31-54. 